\title{
Expression of TRPV4 \\ in the Stimulated Rat Oral Mucous Membrane -Nociceptive Mechanisms of Lingual Conical Papillae-
}

\author{
By \\ Michiko NAKATSUKA and Yasutomo IWAI \\ Department of Oral Anatomy, Osaka Dental University \\ -Received for Publication, January 15, 2009-
}

Key Words: Nociception, TRPV4, pERK, 5HT, Descending pain modulation

\begin{abstract}
Summary: The study was supported by 2006-2007 Aid Program for Overseas Training of the Promotion and Mutual Aid Corporation for Private School of Japan and International Exchange Grant, Osaka Dental University.

We studied the function of TRPV4 expression and its neuronal activation in response to noxious stimulation of oral mucosa. The intermolar region of dorsal lingual eminence (IDLE) of rats was stimulated with $10 \mu \mathrm{l}$ of either normal saline or $5 \%$ formalin. Immunohistological studies of the TRPV4, pERK and serotonin (5HT) expression in designated regions of tongues and brainstems were performed for studying the descending pain modulatory system in response to nociception. Specimens of the experimental IDLE demonstrated a significant increase of TRPV4 activity in particular in stratum basale of conical papillae $(\mathrm{p}<0.01)$. pERK-IR positive neurons were significantly increased in the $\mathrm{RMg}(\mathrm{p}<0.05), \mathrm{Sp5C}(\mathrm{p}<0.05)$ and Md $(p<0.01)$; TRPV4-IR neurons were found to show a similar distribution with pERK-IR cells in the peripheral Sp5C $(p<0.05)$. A significant increase of 5HT expression was observed in the $\mathrm{RMg}(\mathrm{p}<0.01), \mathrm{RPa}(\mathrm{p}<0.01)$ and $\mathrm{ROb}(\mathrm{p}<$ 0.05).

The results suggest that TRPV4 in the oral mucosa is nociceptor of peripheral hyperalgesia, and pERK expression in the $\mathrm{Sp5C}$ is closely related with central hyperalgesia of the nociception. Furthermore, pERK-IR cells of the central 5HT nervous system are activated to accelerate 5HT release for neuronal modulation of the descending pain modulatory system in response to nociception.
\end{abstract}

\section{Introduction}

Transient receptor potential (TRP) vanilloid 4 (TRPV4) is a $\mathrm{Ca}^{2+}$-channel receptor and a member of the TRP superfamily ${ }^{1)}$. TRPV4 is widely found in keratinized epithelial cells, the lung, brain, smooth muscle cells and vascular endothelium, and is activated by hypotonocity, thermal $\left(27^{\circ} \mathrm{C}-35^{\circ} \mathrm{C}\right)$ stimulation, low $\mathrm{pH}, 4 \alpha$-phorbol 12,13-didecanoate ( $4 \alpha$-PDD), and arachidonic acid (AA) etc. ${ }^{2-9)}$. TRPV4 expression evoked by hypotonic stimulation under the existence of inflammatory media (e.g. prostaglandin $\mathrm{E}_{2}: \mathrm{PGE}_{2}$ ) incited C-fiber activity consequently eliciting thermal hyperalgesia ${ }^{10,11)}$. A recent study has observed a wide-spreading distribution of TRPV4 in brain and in particular in the hippocampus, which is a structure closely related with mnemonic formation ${ }^{12)}$. Activation of TRPV4 at $37^{\circ} \mathrm{C}$ depolarized the resting membrane potential in hippocampal neurons by allowing cation influx, and thus increased the excitability of neu- rons ${ }^{12)}$. There have been studies on TRPV4, however, its localization in oral mucous membrane, and reception and transmission of noxious stimulation resulting hyperalgesia are not completely understood.

A recent study has elucidated that regulation of TRP channel expression was activated by mitogen-activated protein kinase (MAPK) of the intracellular signal transduction pathway ${ }^{13)}$. Another study observed that activated extracellular signal-regulated kinase (ERK) took part in increasing TRPV1 by induction of tumor necrosis factor (TNF) $\alpha$ (an inflammatory cytokine) expression in the dorsal root ganglia (DRG) ${ }^{14}$. On the other hand, activation of ERK in the dorsal horn (DH) also induced an increase in the expression of certain neurotransmitters and receptors associated with hyperalgesia and allodynia ${ }^{15)}$. Further, a recent study has reported that activation of ERK affected the serotonin (5-hydroxytryptamine; 5HT) in the nervous system of the descending pain modulatory system by facilitating $5 \mathrm{HT}$ biosynthesis to evoke central 
hyperalgesia ${ }^{16)}$. The studies suggested that ERK, TRP superfamily and central 5HT nervous system are possibly affiliated with nociception, neuronal transmission, central hyperalgesia and descending pain inhibition evoked by nociceptive stimulation of peripheral tissues ${ }^{16-19)}$. However, details concerning the relationships between them were not elucidated.

Our previous study on the TRPV1 ligand by application of capsaicin (CAP) on intermolar region of the dorsal lingual eminence (IDLE) has demonstrated ERK activity in brainstem of rats ${ }^{20,21}$. The study observed a statistically significant increase in phosphorylated ERK (pERK) in the spinal trigeminal nucleus caudal part (Sp5C) of the experimental group, and therefore surmised that there was a plastic change occurring in the modulatory system of brainstem by the noxious CAP stimulation ${ }^{21)}$. In the present study, we aimed at the expression of TRPV4 -which is not reactive to $\mathrm{CAP}-$, and studied reception and neuronal transmission followed by formalin (FOR) stimulation of rat oral mucous membrane. For elucidation of the expression of pERK and TRPV4, central 5HT nervous system affected by TRPV4 nociception, and the neuronal transmission and pain inhibition evoked by FOR stimulation of the IDLE, we investigated, compared and statistically analyzed the significance of expression of 1) TRPV4 and 5HT (an inflammatory mediator) in oral mucosa, 2) TRPV4 and pERK in brainstem, and 3) TRPV4, pERK and 5HT in the central 5HT nervous system.

\section{Materials and Methods}

Materials and methods for the present study were summarized in the Flowchart.

\section{Animal preparation}

Male Wistar rats (250 g body weight; Japan SLC, Shizuoka, Japan; $n=6$ ) were used in this study. The protocol was approved by the Animal Research Committee of Osaka Dental University (No. 07-02021: Investigation of transient receptor potential vanilloid (TRPV) subfamily expression in oral cavity -mechanism and significance-) and implemented in accordance with the ethical guidelines for investigation of experimental pain in conscious animals of the International Association for the Study of Pain $^{22)}$.

\section{Experimental and control groups}

After anesthesia of the rats with sodium pentobarbital $(70 \mathrm{mg} / \mathrm{kg}$; i.p.), the IDLE of rats was stimulated with filter paper discs (diameter $=2 \mathrm{~mm}$ ) soaked with either 10 $\mu 10 \%$ FOR (normal saline, room temperature: $\mathrm{RT}, \mathrm{pH}=$ 7.2; $\mathrm{n}=3$; control) or $10 \mu \mathrm{l} 5 \%$ FOR (RT; $\mathrm{pH}=4.0$; experimental) for 5 minutes. The rats were euthanized and transcardiac-perfused with $100 \mathrm{ml}$ of saline solution fol- lowed by $4 \%$ chilled $\left(0^{\circ} \mathrm{C}-4^{\circ} \mathrm{C}\right)$ paraformaldehyde in 0.1 $\mathrm{M}$ phosphate buffer (PB) at $\mathrm{pH} 7.4$ following the conventional methods.

\section{Tissue preparation and immunohistochemical analysis}

The tongues and brainstems were dissected, placed in the same fixative (tongue: $2 \mathrm{hr}$; brainstem: $24 \mathrm{hr}$ ), and then transferred to $30 \%$ sucrose $(\mathrm{w} / \mathrm{v})$ in $0.1 \mathrm{M} \mathrm{PB}$ for 48 $\mathrm{hr}$ for cryoprotection. The tongues and brainstems were cut into sections (tongue: $10 \mu \mathrm{m}$; brainstem: $30 \mu \mathrm{m}$ ) at $-20^{\circ} \mathrm{C}$ with a Leica CM3050S cryostat (Leica Microsystems, Wetzlar, Germany), and then serially transferred to multi-well tissue culture plates containing $0.1 \mathrm{M}$ Trisbuffered saline (TBS). Frozen sections of each tongue and every sixth section (between $-7.22 \mathrm{~mm}$ and -15.66 $\mathrm{mm}$; distance from the bregma) of each brainstem were collected and processed for immunohistochemical study of the TRPV4, 5HT and pERK expression in the specimens.

The free-floating sections were treated with $0.1 \mathrm{M}$ PB (pH 7.4) containing $0.75 \%$ Triton X-100 (1 hr) and $0.1 \mathrm{M}$ PB containing $3 \%$ goat serum (30 min), immunoreacted with primary and secondary antibodies. The horseradish peroxide reaction was developed in distilled water containing $0.05 \% \quad 3,3^{\prime}$ '-diaminobenzidine tetra hydrochloride (DAB; $2 \mathrm{~min}, \mathrm{RT}$ ), $0.2 \%$ nickel sulfate and $0.01 \%$ hydrogen peroxide by using an Elite $\mathrm{ABC}$ kit (Vector Laboratories, CA, USA). The IDLE specimens were counterstained with $1 \%$ methyl green ( $5 \mathrm{~min}$, RT, MERCK, Germany). The IDLE and brainstem sections were mounted on slides, air-dried, dehydrated in a graded ethanol series, cleared in xylene, and cover-slipped.

The specimens were examined and photographed with an Olympus BX41 light microscope (Olympus, Tokyo, Japan) mounted with an Olympus FX380 3CCD digital camera system (OS: Windows XP, Microsoft, CA, USA). The immunoreactive neurons in the midbrain periaqueductal gray (PAG: from -7.22 to $-8.82 \mathrm{~mm}$; bregma), dorsal raphe nucleus (NRD: from -7.22 to $-9.36 \mathrm{~mm}$; bregma), raphe magnus nucleus (RMg: from -9.90 to $-11.52 \mathrm{~mm}$; bregma), raphe pallidus nucleus (RPa: from -9.90 to $-14.22 \mathrm{~mm}$; bregma), nucleus of the solitary tract (NTS: from -11.52 to -15.66 . $\mathrm{mm}$; bregma), raphe obscurus nucleus (ROb: from -11.70 to $-14.22 \mathrm{~mm}$; bregma), lateral reticular nucleus (LRt: from -13.14 to $-14.94 \mathrm{~mm}$; bregma), area postrema (AP: from -13.68 to $-14.22 \mathrm{~mm}$; bregma), spinal trigeminal nucleus caudal part (Sp5C: from -13.68 to $-15.66 \mathrm{~mm}$; bregma) and the medullary reticular nucleus (Md: from -13.68 to -15.66 $\mathrm{mm}$; bregma) were counted ${ }^{23)}$.

TRPV4- and 5HT-immunoreactive (IR) cells in 10 areas (area $=20 \times 20 \mu \mathrm{m}^{2}$ square) of each IDLE, and TRPV4-, pERK- and 5HT-IR neurons in specimens of the control and experimental groups were counted with a FLvFs soft ware (Flovel Image Filling System, Tokyo, Japan) of the FX380 system. Data of the IR cell/neuron 
Flowchart of the present experiment

\section{Materials:}

Wistar rat (male, $\mathrm{n}=6,250 \mathrm{~g}$ ) (Japan SLC Inc., Japan)

Anesthesia: Sodium pentobarbital (70mg/kg, i.p., Nembutal, Dainippon Sumitomo Pharma, Japan)

Methods:

Stimulated with filter paper discs on the intermolar region of dorsal lingual eminence (IDLE) of rats (10 $\mu 1,5 \mathrm{~min})$

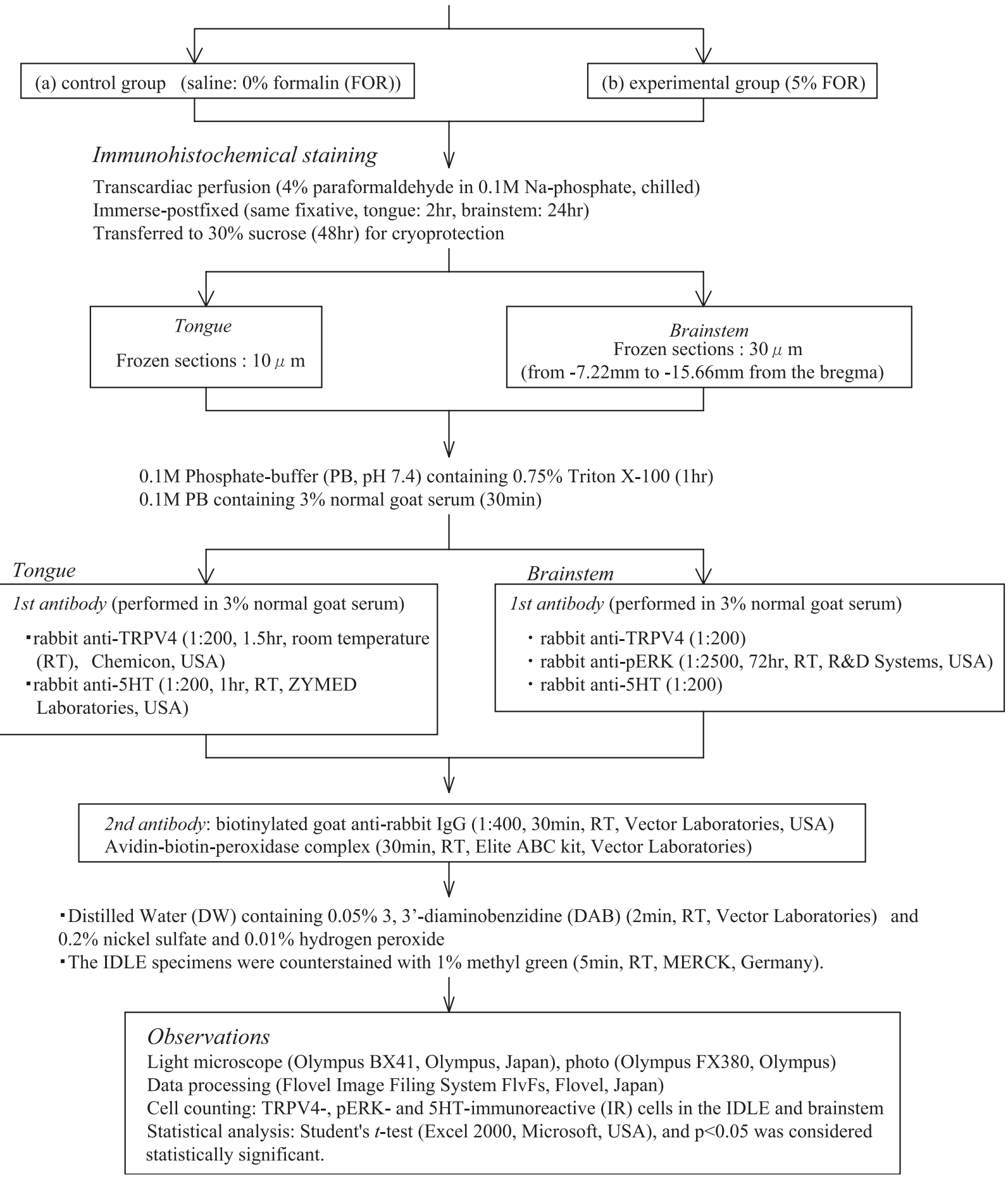

TRPV4- and serotonin (5-hydroxytryptamine; 5HT)-immunoreactive (IR) cells in the intermolar region of the dorsal lingual eminence (IDLE; per $20 \times 20 \mu \mathrm{m}^{2}, 10$ areas per each group), TRPV4-, pERK and 5HT-IR cells in brainstem (designated areas) were counted, and those data are statistically analyzed. 
counts in the IDLE and brainstem of both the control and experimental groups were recorded, summarized and statistically analyzed by using Student's $t$-test (significance: $\mathrm{p}<0.05$; Excel 2000, Microsoft, USA) by a MSWindows XP personal computer (see Flowchart).

\section{Results}

\section{TRPV4- and 5HT-IR cells in the IDLE (Table; Fig. 1)}

\section{Control group}

Distribution of weakly-stained TRPV4-IR cells was localized in stratum basale of IDLE giant conical papillae (Fig. 1A). In contrast, weakly-stained 5HT-IR cells were also indistinct in lamina propria of the IDLE mucosa (Fig. 1C).

\section{Experimental group}

TRPV4-IR cells were observed clearly in all epithelial layers and in particular in stratum basale of the IDLE (Fig. 1B). On the other hand, 5HT-IR cells were dis- tinctly found in lamina propria of the IDLE mucosa (Fig. 1D).

\section{Statistic analysis}

Statistically significant differences of the expression of TRPV4-IR cells (degree of freedom: $D F=15, p<0.01$ ) and 5HT-IR cells $(\mathrm{DF}=18, \mathrm{p}<0.01)$ were found between the control and experimental groups (Table).

The results showing significant increase of TRPV4and 5HT-IR cells in the IDLE suggested that the FOR nociceptive stimulus induced 5HT expression to maintain and enhance TRPV4 activity in the inflammatory IDLE.

2. pERK-IR neurons in brainstem, and $p E R K$ - and TRPV4-IR neurons in the Sp5C (Table; Fig. 2)

Statistically significant differences of pERK expression were demonstrated in the $\mathrm{RMg}(\mathrm{DF}=6, \mathrm{p}<0.05)$, Sp5C $(\mathrm{DF}=22, \mathrm{p}<0.05)$ and $\mathrm{Md}(\mathrm{DF}=17, \mathrm{p}<0.01)$ between the control and experimental groups (Table; Figs. 2A and 2B). In addition, we observed many pERKIR neurons in the nucleus of the NTS and AP of either
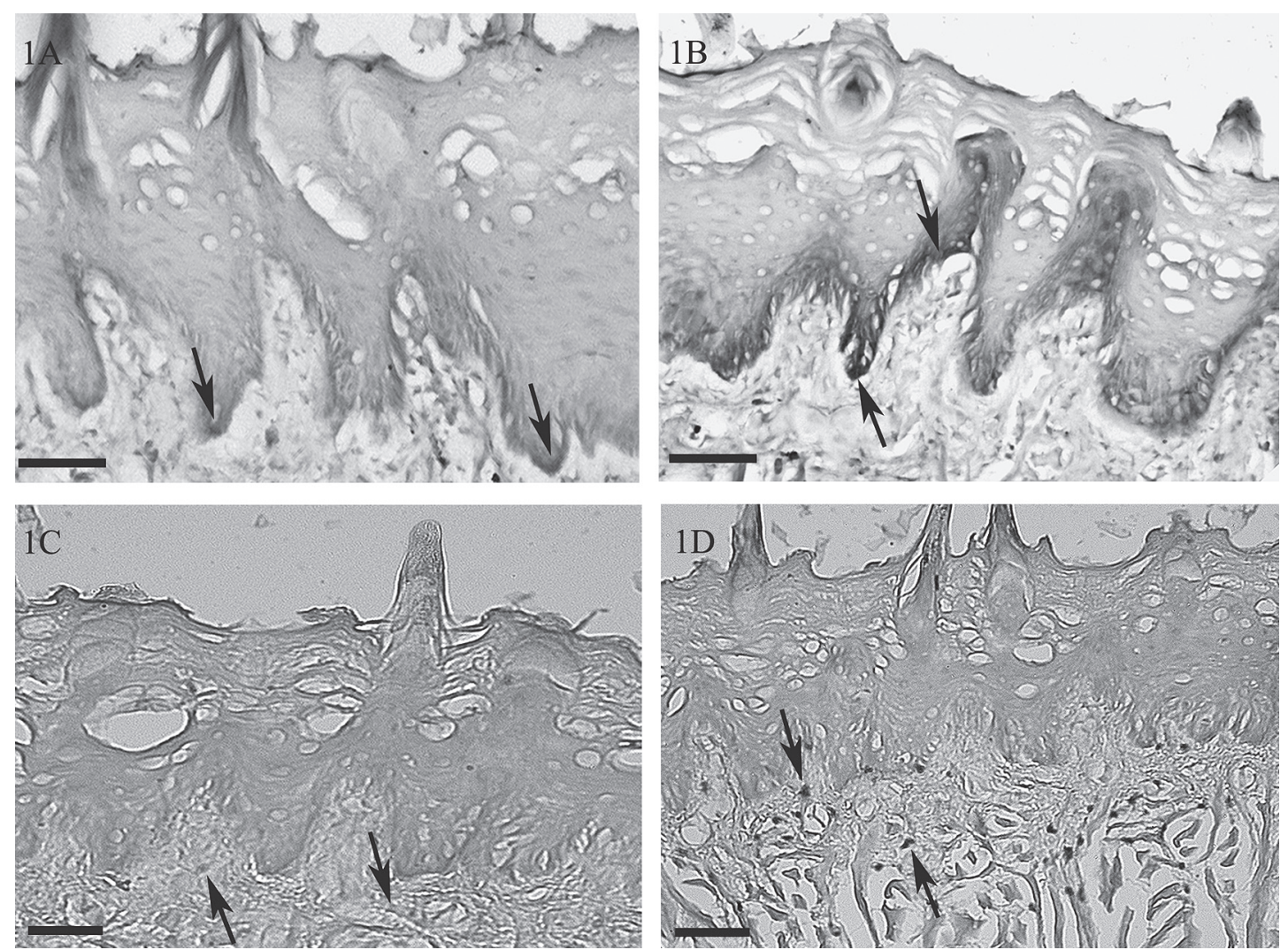

Fig. 1. A and $\mathrm{C}$ are light microscopic images of the control group (saline: $0 \% \mathrm{FOR}$ ), and $\mathrm{B}$ and $\mathrm{D}$ are light microscopic images of the experimental group ( $5 \%$ FOR). The specimens were counterstained with $1 \%$ methyl green ( 5 min, RT; MERCK, Germany). A and B: TRPV4-IR cells in the IDLE (A: scale bar $=60 \mu \mathrm{m}, \mathrm{B}$ : scale bar $=70 \mu \mathrm{m}$ ). C and D: 5HT-IR cells in the IDLE (scale bar $=50 \mu \mathrm{m}$ ).

In comparison with the control group (arrows; Fig. 1A), the experimental group (Fig. 1B) demonstrates distinctive TRPV4 activity in particular in stratum basale (arrows; Fig. 1B) of giant conical filiform lingual papillae.

In the control group, weak immunoreaction is obtained 5HT in lamina propria of the IDLE mucosa (arrows; Fig. 1C). In contrast, 5HT-IR cells are distinctly found in lamina propria of the IDLE mucosa in the experimental group (arrows; Fig. 1D). 

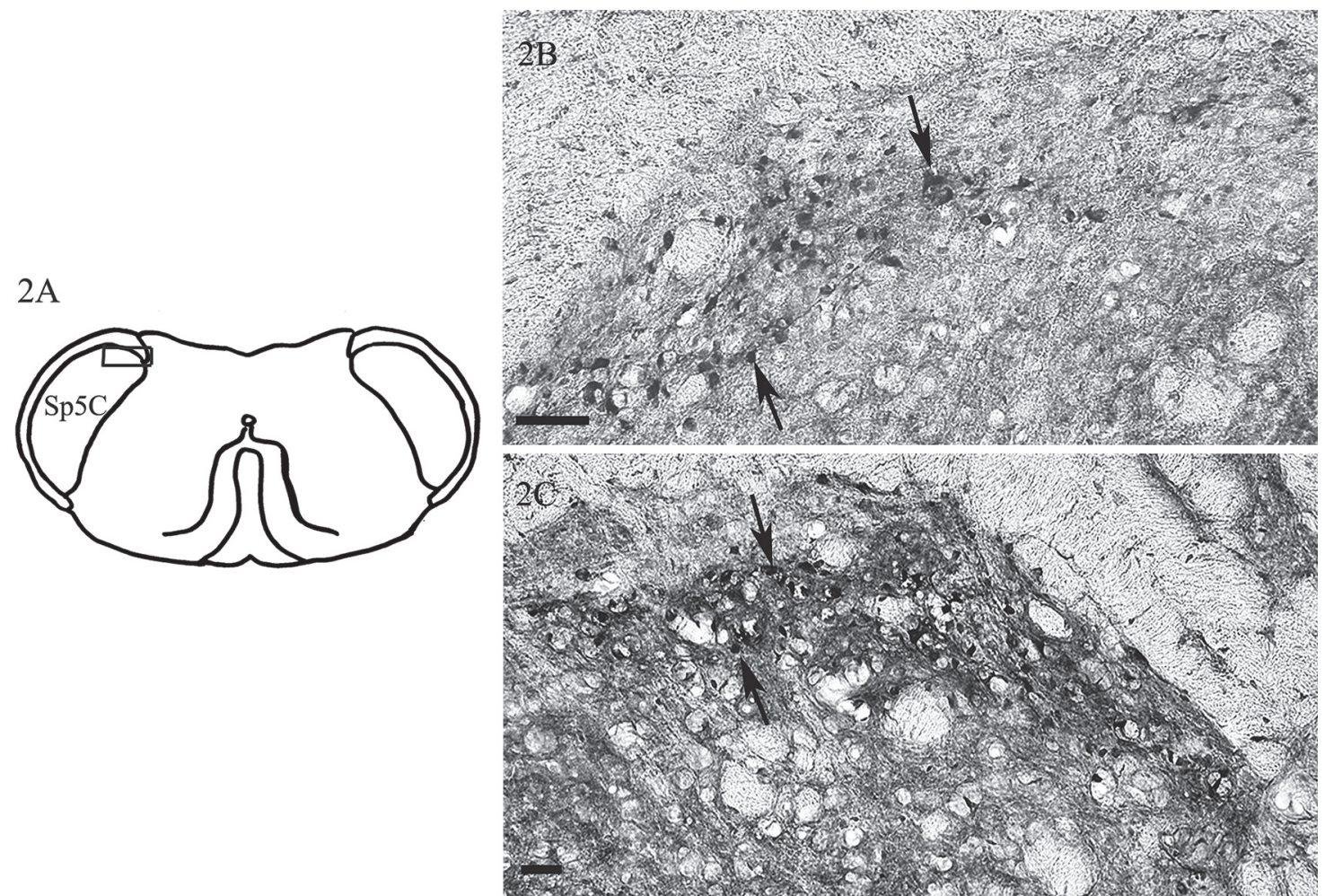

Fig. 2. pERK and TRPV4 immunoreactions in the spinal trigeminal caudal part (Sp5C: bregma $-14.76 \mathrm{~mm}$; experimental group: $5 \%$ FOR). A: Schematic of the Sp5C. The immunoreactions in the boxed area (dorsal part of the Sp5C) is particularly observed in B and C. B: pERK-IR neurons (arrows) in the Sp5C (Scale bar $=100 \mu \mathrm{m})$. C: TRPV4-IR neurons (arrows) in the Sp5C (Scale bar $=50 \mu \mathrm{m})$.

The histology distinctly shows pERK (arrows; Fig. 2B) and TRPV4-IR neurons (arrows; Fig. 2C) distributing in dorsal part of the superficial layer of the Sp5C (arrows).

Table Analysis of immunoreactive cells and neurons in the control and experimental groups.

pERK

\begin{tabular}{|c|c|c|c|c|c|c|c|c|c|c|}
\hline & PAG & NRD & $\mathrm{RMg}$ & $\mathrm{RPa}$ & NTS & $\mathrm{ROb}$ & LRt & $\mathrm{AP}$ & Sp5C & $\mathrm{Md}$ \\
\hline DF & 5 & 6 & 6 & 28 & 44 & 23 & 20 & 6 & 22 & 17 \\
\hline$t$ & -0.5814 & 0.4312 & $-2.5300^{*}$ & 0.7245 & -0.4613 & -0.9844 & 1.1695 & 1.2296 & 2.4584 & $3.3970^{* *}$ \\
\hline \multicolumn{11}{|l|}{ TRPV4 } \\
\hline & $\mathrm{Sp} 5 \mathrm{C}$ & \multicolumn{9}{|l|}{ IDLE } \\
\hline $\mathrm{DF}$ & 10 & \multicolumn{9}{|l|}{15} \\
\hline$t$ & \multicolumn{10}{|c|}{$-2.2435^{*}-6.9963^{* *}$} \\
\hline
\end{tabular}

\begin{tabular}{cccccccc}
$5 \mathrm{HT}$ & & & & & & \\
& PAG & $\mathrm{NRD}$ & $\mathrm{RMg}$ & $\mathrm{RPa}$ & $\mathrm{NTS}$ & $\mathrm{ROb}$ & IDLE \\
\hline $\mathrm{DF}$ & 6 & 5 & 6 & 15 & 22 & 12 & 18 \\
$\mathrm{t}$ & 0.2178 & -0.9004 & $-6.4657^{* *}-3.2607^{* *}-2.3062^{*}$ & $-2.3090^{*}-6.7883^{* *}$
\end{tabular}

The table demonstrates statistically analytical results (Student's $t$-test; Excel 2000, Microsoft) of TRPV4-, pERKand 5HT-IR cells in the IDLE and brainstem $(-7.22 \mathrm{~mm}$ to $-15.30 \mathrm{~mm}$; from bregma; PAG: midbrain periaqueductal gray, NRD: dorsal raphe nucleus, RMg: raphe magnus nucleus, RPa: raphe pallidus nucleus, NTS: nucleus of the solitary tract, ROb: raphe obscurus nucleus, LRt: lateral reticular nucleus, AP: area postrema, Sp5C: spinal trigeminal caudal part and Md: medullary reticular nucleus) of control and experimental groups (each group: $\mathrm{n}=3$ ). The significance of differences is examined by a 2-tailed test for non-paired samples (DF: Degree of Freedom; *: $\mathrm{p}<0.05, * *: \mathrm{p}<0.01)$ 
the control or experimental group. However, no statistic significance between the two groups was observed (Table; NTS: $\mathrm{DF}=44, \mathrm{p}>0.05, \mathrm{AP}: \mathrm{DF}=6, \mathrm{p}>0.05$ ).

The histology was impressed that the number of TRPV4-IR neurons were slightly little than pERKIR neurons in the Sp5C (Figs. 2A and 2C). pERK-IR neurons were distinctly observed in dorsal (more in rostral than in caudal) part of the superficial layer of the Sp5C (Fig. 2B). The expression of TRPV4 and pERK showed significant differences (TRPV4: $D F=10, p<0.05$; pERK: $\mathrm{DF}=22, \mathrm{p}<0.05)$ between the control and experimental groups (Table). The findings in particular showed similar distribution with a significant increase of pERK- and TRPV4-IR neurons in the peripheral Sp5C. This indicated that a rise in TRPV4 activity affected the pERK expression in the $\mathrm{Sp} 5 \mathrm{C}$ continuous with the $\mathrm{DH}$.

\section{Statistical analysis of distribution of 5HT-IR neurons in brainstem (Table; Fig. 3)}

Differences of 5HT expression were significantly observed in the RMg (DF=6, p < 0.01), RPa $(\mathrm{DF}=15, \mathrm{p}<$ $0.01)$ and $\mathrm{ROb}(\mathrm{DF}=12, \mathrm{p}<0.05)$ between the control (Fig. 3A) and the experimental (Fig. 3B) groups (Table; Fig. 3C). No significant differences of 5HT-IR neurons in the NRD were found, however, $60 \%$ increase of the experimental group was noticed (Table; Fig. 3C).
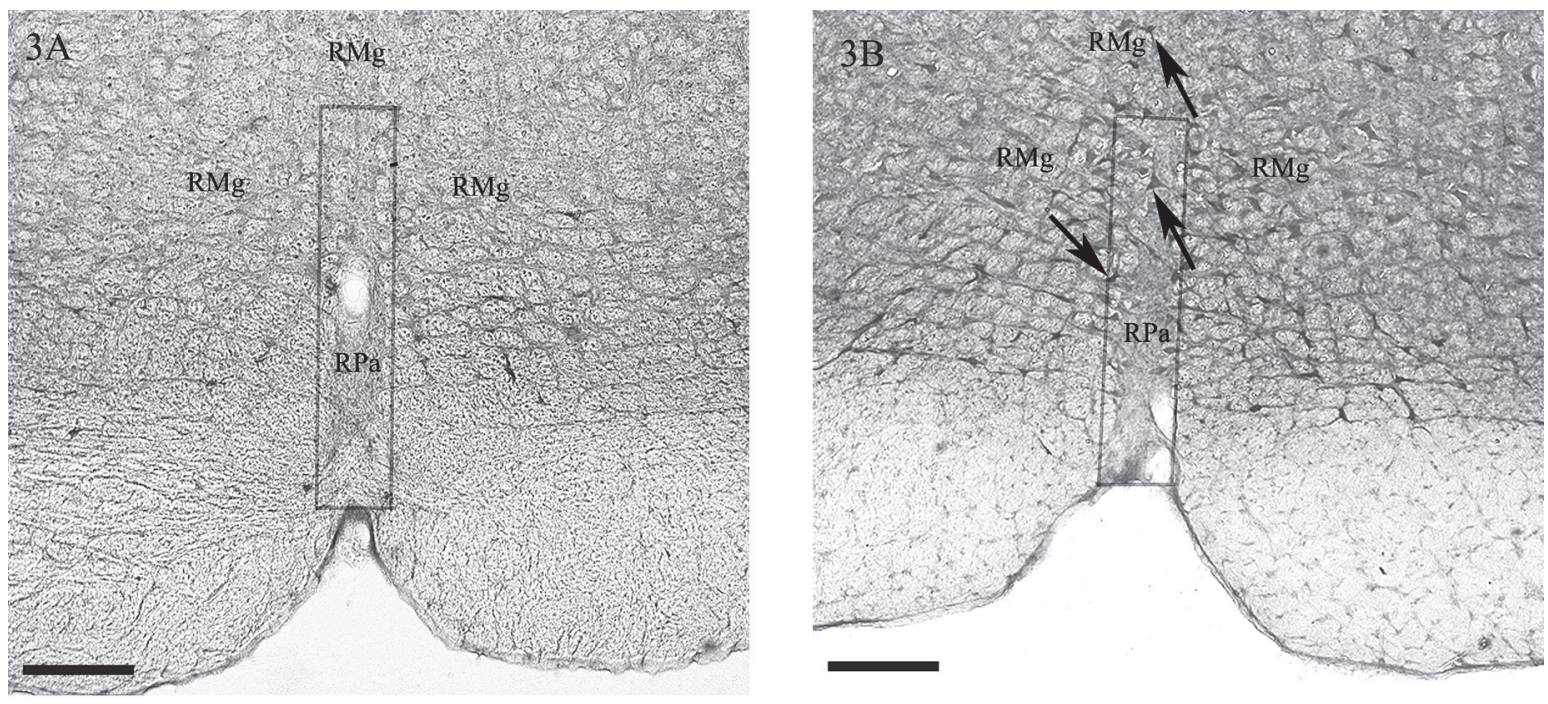

$3 \mathrm{C}$

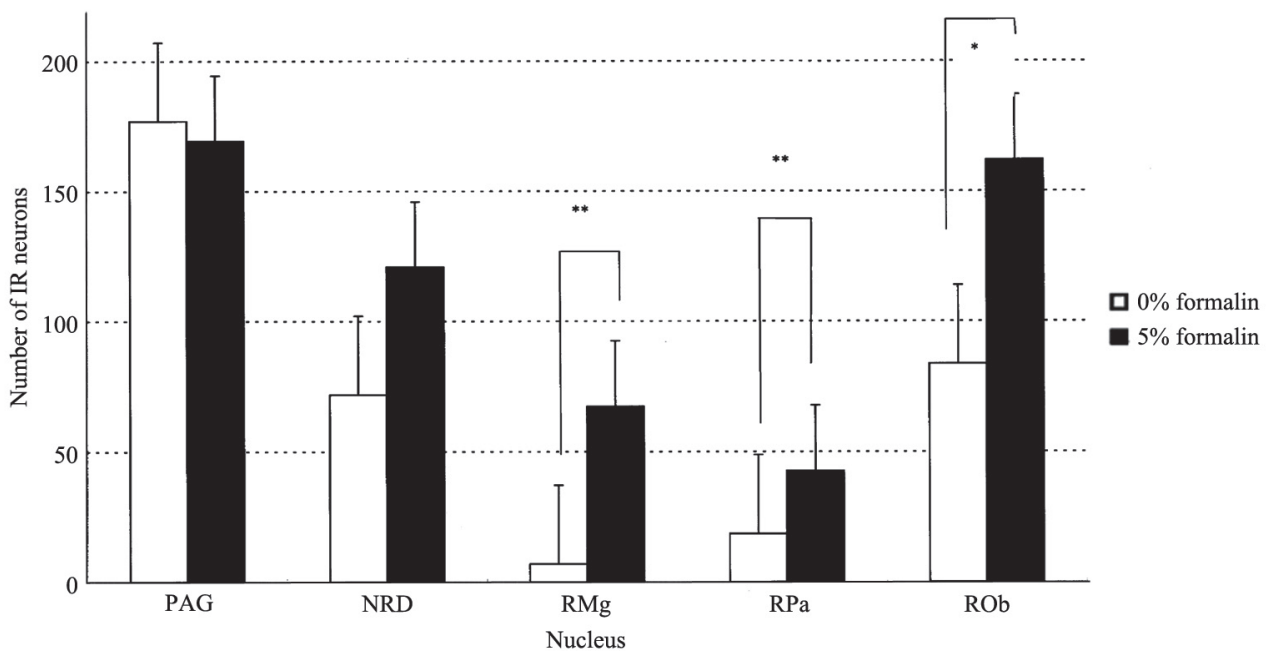

Fig. 3. 5HT-IR neurons in the RPa (boxed area) and RMg $(-12.06 \mathrm{~mm}$; from bregma; Scale bar $=100 \mu \mathrm{m})$. A: Control group $(0 \%$ FOR). B: Experimental group (5\% FOR). C: Mean numbers of 5HT-IR neurons in the brainstem (Error bars: S.E.M).

In the control group (Fig. 3A), a few 5HT-positive neurons are distributed in the RMg and RPa. In contrast, 5HT-positive neurons (arrows) are significantly increased in the $\mathrm{RMg}$ and $\mathrm{RPa}$ in the experimental group (Fig. 3B). Differences of 5HT expression are significantly observed in the RMg, RPa, and ROb between the control and the experimental groups (Fig. 3C; *: p < 0.05, **: p < 0.01). The analysis indicates that a $60 \%$ increase in 5HT-positive neurons in the NRD of the experimental group. 
By inference with the findings of pERK and 5HT activity in brainstem, the results summarize that an increase of ERK activity (pERK; DF=6, $p<0.05$ ) enhances 5HT secretion $(\mathrm{DF}=6, \mathrm{p}<0.01)$ in particular in the $\mathrm{RMg}$ of the experimental brainstem (Table; Fig. 3).

\section{Discussion}

\section{The expression of TRPV4- and 5HT-IR cells in the IDLE}

Nociceptive stimulation of peripheral tissue increases an activated electric current by infiltration of inflammatory mediators including $5 \mathrm{HT}$ and $\mathrm{PGE}_{2}$, and then induces a fall (from $43^{\circ} \mathrm{C}$ to $35^{\circ} \mathrm{C}$ ) of temperature threshold of TRPV1 activity ${ }^{24,25)}$. On the other hand, TRPV4 gave rise to $\mathrm{C}$-fiber activity under co-existence of inflammatory mediators including $\mathrm{PGE}_{2}$ and hypotonic stimulation ${ }^{10,11)}$.

In the present study, we stimulated the IDLE with an inflammatory agent of hypotonic FOR $(\mathrm{pH}=4.0)$, and observed significant differences of TRPV4 distribution in the IDLE between the control and experimental groups (Table; DF=15, $\mathrm{p}<0.01$ ); TRPV4 usually shows optimal activity under $\mathrm{pH} 4.0$ environment ${ }^{6}$. In contrast, we found a statistically significant increase in 5HT-IR cells in IDLE lamina propria of the experimental group (Table; $\mathrm{DF}=18, \mathrm{p}<0.01)$. The present results indicated that there were specific FOR inflammatory reactions with distinct increase in distribution of TRPV4- and 5HT-IR cells in the experimental IDLE; the similar histology has been described in a previous study concerning TRPV1, which is of the same TRP superfamily with TRPV4, in peripheral tissue of FOR stimulation ${ }^{25}$.

On the other hand, a study has stressed that TRPV4 expression was affected by certain crosstalk occurring between osmotic pressure and temperature changes, and mentioned that inflammatory acidosis, inflammatory mediators and $\mathrm{H}^{+}$ions were also factors regulating microenvironments to favor TRPV4 activity ${ }^{10)}$. The nociception gave rise to AA isolation from the cell membrane, and resulted in $\mathrm{PGE}_{2}$ production to activate an intercellular signal pathway concerning TRPV4 phosphorylation in a cascade maintaining TRPV4 activity eliciting hyperalgesia/peripheral sensitization ${ }^{13,26,27)}$. Another study has elucidated that inflammatory mediators including bradykinin (BK), substance P (SP), $\mathrm{PGE}_{2}, 5 \mathrm{HT}$ and histamine cooperated to cause TRPV4-induced hyperalgesia ${ }^{28)}$. The same study also observed that $\mathrm{PGE}_{2}$ and $5 \mathrm{HT}$ particularly cooperate to bring about the hyperalgesia mediated by the cyclic adenosine $3^{\prime}, 5^{\prime}$ '-monophosphate (cAMP) pathway ${ }^{28)}$. Our previous study demonstrated TRPV4 and SP showing similar localization in oral mucosa ${ }^{29)}$. The present results indicated that FOR stimulation enhanced TRPV4 nociception of the IDLE leading to peripheral hyperalgesia ${ }^{28,30)}$.
2. pERK-IR neurons in brainstem, and $p E R K$ - and TRPV4-IR neurons in the Sp5C

Some studies have reported that acute nociception in CAP and FOR stimuli of peripheral tissues (e.g., rat hind paw) increased secretion of neurotransmitter such as SP in DH nerve endings, as well as noticed an increase in ERK phosphorylation mediated by neurokinin-1 receptors in the DH I and $\mathrm{II}_{0}^{31-34)}$. Subsequently, ERK was activated to induce an increase in DRG TRPV1 by TNFa activity ${ }^{14)}$. TRPV1 distributed in primary afferent presynaptic terminals has been elucidated to play a role in activating $\mathrm{Ca}^{2+}$ influx, and release of glutamic acid and SP of nerve fiber ${ }^{14,27,35)}$. The studies hinted at that acute inflammatory nociception of peripheral tissues evoked ERK activation of secondary neurons to raise TRPV1 activation $^{14,27,35)}$. On the other hand, a recent study has observed that the immunoreactive TRPV4 was coexpressed with protease-activated receptor $2\left(\mathrm{PAR}_{2}\right)$, calcitonin gene-related peptide (CGRP) and SP in superficial laminae I and II of the DH containing nerve fibers from the pseudounipolar DRG neurons ${ }^{30}$. It was also noted that $\mathrm{PAR}_{2}$-agonist sensitized TRPV4 $\mathrm{Ca}^{2+}$ signals and currents of the primary afferent presynaptic terminals. The same study also mentioned that $4 \alpha$-PDD and hypotonic solutions stimulated SP and CGRP release from the spinal $\mathrm{DH}^{30)}$.

Our previous study on CAP nociceptive stimulation of the IDLE observed a significant increase of pERK-IR expression in the $\mathrm{NTS}^{21}$. In the present study, we did not observe a significant increase in NTS pERK-IR expression evoked by FOR stimulation of the IDLE ( $\mathrm{DF}=44$, $\mathrm{p}>0.05)$. In contrast, we observed significant increase in the number of $\mathrm{pERK}$ neurons $(\mathrm{DF}=22, \mathrm{p}<0.05)$ in the $\mathrm{Sp} 5 \mathrm{C}$, which is a structure showing similar histology and continuous with the $\mathrm{DH}^{31-34)}$. The present study on FOR nociception of the IDLE observed a significant increase in the expression of TRPV4 and pERK of the Sp5C, showing similar histology of our previous study on TRPV1- and pERK-IR in the Sp5C evoked by CAP stimulation of the IDLE, and thus suggested that a rise in TRPV4 and TRPV1 activity affected the pERK expression in the $\mathrm{Sp} 5 \mathrm{C}$ alike ${ }^{21)}$. This increase also indicated that there was a mechanism of central hyperalgesia evoked by peripheral nociceptive stimulation ${ }^{21)}$. However, the present (FOR) study showing different histology with our previous (CAP) study in the NTS reflected that there were different receptors activated by FOR stimulation of the IDLE, because essentially TRPV1 is but TRPV4 is not a ligand of CAP.

One study on c-Fos expression in brainstem evoked by CAP stimulation of lingual dorsal mucosa has elucidated a distinct increase in the nucleus of NTS but a discrete distribution in the reticular formation, which contains the Md situated between the Sp5C and NTS; the structure receives kinds of sensory information connecting to the autonomic nerve nuclei including thalamus and hypo- 
thalamus $^{36)}$. Some studies have pointed out that vomiting reflex elicited by AP via NTS was evoked with neuronal inputs either directly or indirectly onto the trigeminal nerve by CAP nociceptive stimulation of nasal and oral mucous membrane ${ }^{36,37)}$. Our previous study on CAP nociception of lingual mucosa observed a distinct $p E R K$ but indistinct c-Fos expression in the NTS, and therefore it was assumed that there was an active informational input via NTS towards the AP, which was functionally a chemoreceptor trigger zone ${ }^{21,36,38,39)}$. Some studies further mentioned that divisions of the lingual nerve projecting to the NTS also activate the chorda tympani converging towards the lateral aspect of NTS rostrum, hence interactions between the two nerves possibly occur by CAP stimulation ${ }^{36,40,41)}$. However, nerve fibers from NTS secondary neurons of the lingual and chorda tympani nerves direct via the dorsal trigemino-thalamic tract and medial lemniscus, respectively; both eventually distribute into the ventral posteromedial nucleus (VPM) of thalamus ${ }^{36)}$.

\section{Expression of 5HT-IR neurons in brainstem}

The brain contains a central 5HT nervous system which plays an important part in the descending pain inhibitory system ${ }^{42)}$. Activation of ERK in the 5HT nervous system promoted conversion of tryptophan hydroxylase (TPH; a 5HT synthetic enzyme) into 5-Hydroxytryptophan (5-HTP), and thus increased 5HT production to induce central hyperalgesia of $\mathrm{DH}$ neurons by activating 5HT3 receptors in the $\mathrm{DH}^{16,25,43-45)}$. Another study further reported that activation of ERK in the DH increased the expression of neurotransmitters and related receptors, and therefore induced hyperalgesia and allodynia ${ }^{15)}$.

Neuronal input from the PAG, lateral rostral ventromedial medulla (RVM), and collaterals of the central RVM 5HT neurons induced an increase in the release of 5 HT by nociceptive stimulation of peripheral tissues ${ }^{46,47)}$. On the other hand, the RMg nucleus of the RVM has been reported to be a structure mainly composed of 5HT neurons; it sends out nerve fibers descending with the dorsolateral funiculus (DLF) towards the DH to induce primary sensory nerve fiber endings to secrete neurotransmitters for inhibiting secondary neuron activity, and thus analgesia develops ${ }^{46)}$. A recent study of $\operatorname{Lmx}$ $1 b^{f / f / p}$ mice, which lacking the central 5HT nervous system, has reported an enhanced pain reaction, and it was postulated that the system took an important part in analgesia evoked by FOR/CAP stimulation ${ }^{45}$.

In the present study, we observed significantly different distribution of pERK-IR neurons in the $\mathrm{RMg}(\mathrm{DF}=6$, $\mathrm{p}<0.05)$, Sp5C $(\mathrm{DF}=22, \mathrm{p}<0.05)$ and the $\mathrm{Md}(\mathrm{DF}=17$, $\mathrm{p}<0.01$ ) of the medullar reticular formation in the FORstimulated experimental group. We noticed a $34 \%$ increase of pERK-IR cells in particular in the $\mathrm{PAG}(\mathrm{DF}=5$, $p>0.05)$ of the experimental group, however, no significant differences in the midbrain PAG, NRD ( $\mathrm{DF}=6$, $\mathrm{p}>0.05), \mathrm{RPa}(\mathrm{DF}=28, \mathrm{p}>0.05)$ and the $\mathrm{ROb}(\mathrm{DF}=23$, $\mathrm{p}>0.05)$ located dorsally at a same level of the RPa were demonstrated between the experimental and control groups. On the other hand, a significant increase in the 5HT-IR cells of the RMg (DF=6, p < 0.01), RPa (DF= $15, \mathrm{p}<0.01)$ and $\mathrm{ROb}(\mathrm{DF}=12, \mathrm{p}<0.05)$ of the FORstimulated experimental group was observed. This summarizes that an increase of ERK activity enhances 5HT secretion in particular the RMg (pERK: $\mathrm{DF}=6, \mathrm{p}<0.05$; $5 \mathrm{HT}: \mathrm{DF}=6, \mathrm{p}<0.01)$ of the central $5 \mathrm{HT}$ nervous system.

On-cells, off-cells and neutral-cells of the RVM neurons were differentiated by the specific property of pain transmission (i.e., promotion, inhibition and unchanging) in the $\mathrm{DH}$, respectively. However, a recent study has reported that the RMg was a functional circuit showing fluctuation in activity of on-cells, off-cells and neutral-cells by $5 \mathrm{HT}$ expression changes in the $\mathrm{RVM}^{48)}$. Although the central 5HT nervous system has been found to be totally composed of neutral-cells, the present study speculated that the increase in 5HT expression of the system also affected the activity of on-cells and offcells ${ }^{49}$. We observed that FOR stimulation of the IDLE evoked an increase in pERK- and 5HT-IR neurons of the central 5HT nervous system, and summarized that the expression of TRPV4, pERK and 5HT also activates the descending pain modulatory system. However, since details of the descending pain modulatory system are still unclear. Further studies to clarify interactions of TRPV4, pERK and 5HT in the Sp5C, and how they affect on-cell, off-cell and neutral-cell promotion performance (central hyperalgesia) and inhibition (descending pain inhibition) of pain will be our next goal.

\section{Acknowledgement}

We would like to express our gratitude to staffs of the Department of Oral Anatomy, Osaka Dental University, and Professor Shin Je-Won, DDS and PhD, and Associate Professor Jue Seong-Suk, DDS and $\mathrm{PhD}$, of the Department of Oral Anatomy, Kyung-Hee University, for their valuable assistance in this research and helpful suggestions.

The Laboratory Animal Facilities, Tissue Culture Facilities and Dental Bioscience Facilities I of the Institute of Dental Research, Osaka Dental University, were used to perform this study.

The study was supported by 2006-2007 Aid Program for Overseas Training of the Promotion and Mutual Aid Corporation for Private School of Japan and International Exchange Grant, Osaka Dental University. 


\section{References}

1) Nilius B, Vriens J, Prenen J, Droogmans G and Voets T. TRPV4 calcium entry channel: a paradigm for gating diversity. Am J Physiol Cell Physiol 2004; 286:195-205.

2) Chung MK, Lee HS and Caterina MJ. Warm Temperature Activate TRPV4 in Mouse 308 Keratinocytes. J Biol Chem 2003; 278:32037-32046

3) Guler AD, Lee HS, Iida T, Shimizu I, Tominaga M and Caterina MJ. Heat-Evoked Activation of the Ion Channel, TRPV4. J Neurosci 2002; 22:6408-6414.

4) Liedtke $W$ and Simon SA. A possible role for TRPV4 receptors in asthma. Am J Physiol Lung Cell Mol Physiol 2004; 287: 269-271.

5) Mizuno A, Matsumoto N, Imai M and Suzuki M. Impaired osmotic sensation in mice lacking TRPV4. Am J Physiol Cell Physiol 2003; 285:C96-C101.

6) Suzuki M, Mizuno A, Kodaira K and Imai M. Impaired pressure sensation in mice lacking TRPV4. J Biol Chem 2003; 278: 22664-22668.

7) Vriens J, Owsianik G, Fisslthaler B, Suzuki M, Janssens A, Voets T, Morisseau C, Hammock BD, Fleming I, Busse R and Nilius B. Modulation of the $\mathrm{Ca}^{2+}$, Permeable Cation Channel TRPV4 by Cytochrome P450 Epoxygenases in Vascular Endothelium. Circ Res 2005; 97:908-915.

8) Watanabe H, Vriens J, Suh SH, Benham CD, Droogmans G and Nilius B. Heat-evoked Activation of TRPV4 Channels in a HEK 293 Cell Expression System and in Native Mouse Aorta Endothelial Cells. J Biol Chem 2002; 277:47044-47051.

9) Watanabe H, Vriens J, Prenen J, Droogmans G, Voets T and Nilius B. Anandamide and arachidonic acid use epoxyeicosatrienoic acids to activate TRPV4 channels. Nature 2003; 424:434-438.

10) Haber NA, Dina OA, Yeh JJ, Parada CA, Reichling DB and Levine JD. Transient receptor potential vanilloid 4 is essential in chemotherapy-induced neuropathic pain in the rat. J Neurosci 2004; 24:4444-4452.

11) Tominaga M. Capsaicin receptor TRPV1. Brain Nerve 2008; 60: 493-501.

12) Shibasaki K, Suzuki M, Mizuno A and Tominaga M. Effects of body temperature on neural activity in the hippocampus: Regulation of resting membrane potentials by transient receptor potential vanilloid 4. J Neurosci 2007; 27:1566-1575.

13) Obata $\mathrm{K}$ and Noguchi K. Roles of MAP kinase in nociceptive pathways. J Clin Exp Med 2007; 223:668-673.

14) Hensellek S, Brell P, Schaible HG, Brauer R and Banchet GS. The cytokine TNF $\alpha$ increases the proportion of DRG neurons expressing the TRPV1 receptor via the TNFR1 receptor and ERK activation. Mol Cell Neurosci 2007; 36:381-391.

15) Ji RR, Befort K, Brenner GJ and Woolf CJ. ERK MAPK kinase activation in superficial spinal cord neurons induces prodynorphin and NK-1 upregulation and contributes to persistent inflammatory pain hypersensitivity. J Neurosci 2002; 22:478-485.

16) Imbe $\mathrm{H}$ and Senba E. The role of descending pain modulatory system in chronic pain state: with special reference to serotonergic neurons in the RVM. J Clin Exp Med 2007; 223:695-699.

17) Obata K, Katsura H, Mizushima T, Yamanaka $H$ and Kobayashi $K$. TRPA1 induced in sensory neurons contributes to cold hyperalgesia after inflammation and nerve injury. J Clin Invest 2005; 115: 2393-2401.

18) Katsura H, Obata K, Mizushima T, Yamanaka H and Kobayashi K. Antisense knock down of TRPA1, but not TRPM8, alleviates cold hyperalgesia after spinal nerve ligation in rats. Exp Neurol 2006; 200:112-123.

19) Obata K, Kobayashi K, Fukuoka $T$ and Noguchi K. Cold receptors in the DRG: basic science and clinical implications. Reviews in Analgesia 2006; 9:31-44.

20) Kutuzov H and Sicher H. The Filiform and the conical papillae of the tongue in the white rat. Anat Rec 1951; 110:276-288.

21) Nakatsuka M, Jue SS and Iwai Y. pERK expression in the rat brainstem following capsaicin stimulation on rat circumvallate papillae, $7^{\text {th }}$ World Congress of Neuroscience [CD-ROM] 2007; POS-SAT-072.

22) Zimmerman, M. Ethical guidelines for investigation of experimental pain in conscious animals, Pain 1983; 16:109-110.

23) Paxinos $G$ and Watson $C$. The rat brain in stereotaxic coordination $6^{\text {th }}$ edition, London: Academic Press, 2007.

24) Tominaga $M$ and Caterina MJ. Thermosensation and pain. J Neurobiol 2004; 61:3-12.

25) Tominaga M. Inflammatory pain and TRP channels. Pain Clinic 2008; 29:179-188.

26) Nakatsuka T, Furue H, Yoshimura $M$ and Gu JG. Activation of central terminal vanilloid receptors and $\alpha \beta$-methylene-ATPsensitive $\mathrm{P} 2 \mathrm{X}$ receptors reveals a converged synaptic activity onto the deep dorsal horn neurons of the spinal cord. J Neurosci 2002; 22:1228-1237.

27) Nakatsuka T, Fujita $T$ and Kumamoto E. Pain mechanisms. Physiological findings. Clin Orthop Surg 2007; 42:539-544.

28) Haber NA, Dina OA, Joseph EK, Reichling DB and Levine JD. A transient receptor potential vanilloid 4-dependent mechanism of hyperalgesia is engaged by concerted action of inflammatory mediators. J Neurosci 2006; 26:3864-3874.

29) Nakatsuka M, Kumabe S, Takama $K$ and Iwai Y. Expression of TRPV4 and substance $\mathrm{P}$ in rat oral mucosa following noxious stimulation. Jpn J Oral Biosci 2008; 50 (Suppl.):195.

30) Grant AD, Cottrell GS, Amadesi S, Trevisani M, Nicoletti P, Materazzi S, Altier C, Cenac N, Zamponi GW, Bautista-Cruz F, Lopez CB, Joseph EK, Levine JD, Liedtke W, Vanner S, Vergnolle N, Geppetti P and Bunnett NW. Protease-activated receptor2 sensitizes the transient receptor potential vanilloid4 ion channel to cause mechanical hyperalgesia in mice. J Physiol 2007; 578: 715-733.

31) Firner M, Greffrath $\mathrm{W}$ and Treede RD. Phosphorylation of extracellular signal-related protein kinase is required for rapid facilitation of heat-induced currents in rat dorsal root ganglion neurons. Neuroscience 2006; 143:253-263.

32) Ji RR, Baba H, Brenner GJ and Woolf CJ. Nociceptive-specific activation of ERK in spinal neurons contributes to pain hypersensitivity. Nature Neuroscience 1999; 2:1114-1119.

33) Ji RR, Kohno T, Moore KA and Woolf CJ. Central sensitization and LTP: do pain and memory share similar mechanisms? Trends in Neurosciences 2003; 26:696-705.

34) Zhuang ZY, Gerner P, Woolf CJ and Ji RR. ERK is sequentially activated in neurons, microglia, and astrocytes by spinal nerve ligation and contributes to mechanical allodynia in this neuropathic pain model. Pain 2005; 114:149-159.

35) Vriens J, Watanabe H, Janssens A, Droogmans G, Voets T and Nilius B. Cell swelling, heat, and chemical agonists use distinct pathways for the activation of the cation channel TRPV4. PNAS 2004; 101:396-401.

36) Carstens E, Saxe I and Ralph R. Brainstem Neurons Expressing c-Fos Immunoreactivity Following Irritant chemical Stimulation of the rat's tongue. Neuroscience 1995; 69:939-953.

37) Boucher Y, Saimons C, Cuellar J, Jung SW, Carstens M and Carstens E. Activation of brain stem neurons by irritant chemical stimulation of the throat assessed by c-fos immunohistochemistry. Exp Brain Res 2003; 148:211-218.

38) Hamilton RB and Norgren R. Central projections of gustatory nerves in the rat. J Comp Neurol 1984; 222:560-577.

39) Jacquin MF, Semba K, Rhoades RW and Egger MD. Trigeminal primary afferents project bilaterally to dorsal horn and ipsilaterally to cerebellum, reticular formation, and cuneate, solitary, supratrigeminal and vagal nuclei. Brain Res 1982; 246:285-291.

40) Segade LG, Quintanilla JS and Cobos AR. Contralateral projections of trigeminal mandibular primary afferents in the guinea pig 
as seen by transganglionic transport of horseradish peroxidase. Brain Res 1990; 506:267-280.

41) Simons CT, Boucher Y and Carstens E. Suppression of central taste transmission by oral capsaicin. J Neurosci 2003; 23:978985.

42) Yoshimura $M$ and Furue $H$. Mechanisms for the anti-nociceptive actions of the descending noradrenergic and serotonergic systems in the spinal cord. J Pharmacol Sci 2006; 101:107-117.

43) Caterina MJ, Leffler A, Malmberg AB, Martin WJ, Trafton J, Petersen-Zeitz KR, Koltzenburg M, Basbaum AI and Julius D. Impaired nociception and pain sensation in mice lacking the capsaicin receptor. Science 2000; 288:306-313.

44) Suzuki R, Rygh LJ and Dickenson AH. Bad news from the brain: descending 5-HT pathways that control spinal pain processing. Trends Pharmacol Sci 2004; 25:613-617.

45) Zhao ZQ, Chiechio S, Sun YG, Zhang KH, Zhao CS, Scott M, Johnson RL, Deneris ES, Renner KJ, Gereau IV RW and Chen
ZF. Mice lacking central serotonergic neurons show enhanced inflammatory pain and an impaired analgesic response to antidepressant drugs. J Neurosci 2007; 27:6045-6053.

46) Imbe $H$, Okamoto $K$, Okamura $T$, Kumabe $S$, Nakatsuka $M$, Aikawa F, Iwai Y and Senba E. Effects of peripheral inflammation on activation of ERK in the rostral ventromedial medulla. Brain Res 2005; 1063:151-158.

47) Smith VA, Beyer CE and Brandt MR. Neurochemical changes in the RVM associated with peripheral inflammatory pain stimuli. Brain Res 2006; 1095:65-72.

48) Fields H. State-dependent opioid control of pain. Nat Rev Neurosci 2004; 5:565-575.

49) Roychowdhury SM and Heinricher MM. Effects of iontophoretically applied serotonin on three classes of physiologically characterized putative pain modulating neurons in the rostral ventromedial medulla of lightly anesthetized rats. Neurosci Lett 1997; 226: 136-138. 